\title{
Education as an Aspiration for Girls of Turkish Muslim Origin in Germany
}

\author{
Pinar Burcu Güner \\ ORCID: https://orcid.org/0000-0002-1577-8726 \\ (Bielefeld School of Public Health, Department of Epidemiology and International Public Health, \\ pburcu.guner@gmail.com)
}

In the main study, there were 20 focus groups (five to eight girls in each group), followed by a socio-economic questionnaire (to control conversion factors such as; migration background, ethnicity, religion, and gender) and 25 individual life history interviews with the girls who participated in the focus groups (to analyze the personal experiences of inequality). In the main study, the interview guidelines were structured to investigate the girls of a Turkish origin`s perceived opportunities, inequalities, and how they removed these limitations (agency) for a good life. As a result, the research was centered on two main concepts; a good life and good school education opportunities.

\section{Introduction}

In Europe, religion is shown to be an essential element of Turkish identity in countries where they are most stigmatized (Herzog-Punzenberger \& Schnell 2012). The second generation, that is the individuals whose parents migrated to Europe, but who themselves were born in Europe, sits between forces that often pull them in different directions: their immigrant parents, their wider family and community networks, their friends, their schools, and the society at large into which they were born or moved as a child (Schneider \& Crul 2012, 206). Considering that the participants of this research are Muslim origin Turkish origin girls; it is worthy to highlight that being Muslim is the most mentioned reason in public defamatory discourse Muslims and devaluing their family of origin is a danger to the lives of these young people (Wilpert 2013,122).

The European debate has thus misconstrued the actual state of affairs. Its image of a large majority of Muslim youths who are strongly religious and hold radical Islamic views do not resemble reality. Instead, this attitude pushes them out of society (Crul \& Mollenkopf 2012 , 253). Europe uses religion, citizenship, and ethnonational-origin to draw social 
boundaries, not a race, which remains a taboo term (Tran et al. 2012,161). Baysu and colleagues $(2011,128)$ highlight that both social identity theory and stereotype threat research have associated a dual identity strategy with increased vulnerability to identity threat, which is relevant to - this research. Identity threat means that minority groups may interpret majority peoples` reactions as threatening. Identity threat to marginalize identities from another angle reveals that when integration is for 'the moral good', what happens in practice is the reproduction of a hierarchical insider/outsider structure which prescribes conformity and frequently diminishes the acculturation responsibilities of the non-Muslim mainstream (Bowskill et al. 2007, 807).

\section{Theoretical Framework: Concept of 'Wellbeing' in Capability Approach}

The Capability Approach is primarily a framework of thought, a mode of thinking about normative issues; hence a paradigm that can be used for a wide range of evaluative purposes. The Capability Approach identifies social constraints that influence and restrict both the wellbeing as well as the evaluative exercises (Robeyns 2005, 96).

According to this approach, it is necessary to prepare the material and institutional environment so that people are actually able to function for the life they value (Nussbaum $2000,235)$. Taken this way, capabilities are opportunities which are available for people to turn them into valuable actions into functionings ${ }^{1}$ (in other words opportunities) which may help people to have a valuable life. Sen discusses $(1999,75)$ functionings are 'the various things' a person may value doing or being. The Capability Approach draws attention to what a person can do with their current capabilities and what limits people in having a good life. Functionings are defined as "the various things a person may value doing or being" (Sen 1999). In other words, functionings are valuable activities and states that make up people`s wellbeing in terms of being healthy and well- nourished, being safe, being educated, having a good job, and being able to visit loved ones. People use capabilities to have valuable functionings for their wellbeing. For example, when people`s basic need for food is met, they enjoy the functioning of being well-nourished.

According to the Capability Approach, wellbeing, justice and development should be conceptualized in terms of people's capabilities to function; that is, their effective opportunities to undertake the actions and activities that they want to engage in, and be whom they want to be. These beings and doings, which Sen is framing as functioning, together constitute what makes a life valuable. Functioning's include working, resting, being literate, being healthy, being part of a community, being respected, and so forth.

1 Functionings are states of 'being and doing' such as being well-nourished, having shelter. 


\section{Methods}

A pilot study was necessary in order to decide how suitable the data collection methods and methodology were for addressing the research questions, as well as figuring out how to implement the concepts of the Capability Approach and contribute to the qualitative knowledge of the Capability Approach. Pilot study was conduct in order to understand the life, culture and values of young people of immigrant origin to better design the research goals, rationale, questions and data collection methods. Researcher entered the field knowing only grounded theory methodology.

Focus groups interview methods was used in order to obtain the necessary amount of data in a short time. The interview guidelines had open questions such as: What are your everyday activities? How do you spend your free time? These were designed to facilitate an understanding of youth culture as well as break the ice. How young women defined a good life for themselves and for other girls their age living in Germany or in any part of the world, how they perceived their existing opportunities for having a good life in Germany and what they interpreted as obstacles to gaining these opportunities to live a good life. The data was collected from schools that had agreed to take part in the data collection. Only girls who had volunteered were interviewed. Data was collected from six focus groups in two different schools in Gütersloh. Each focus group constituted of five to eight girls, who were aged between 14 and 16 years old.

The findings of the pilot study revealed that girls believed that a 'good education' is fundamental for a 'good life' in Germany, i.e. in order to be valued and accepted by the German society. As challenges, the girls identified discrimination and stereotypes, both at school and in society that limited their opportunity to have a good life and a good school education. There was not enough data to analyze the girls' perception of their existing opportunities, interpreted inequalities, or their resources to use agency to overcome these challenges. Another imperative result of the pilot data was that self-awareness of their own identity and identity development was key for the girls. After the pilot study, the research was re-designed to prepare for the main data collection.

\section{Re-Designing the Research After the Pilot Study}

The research design focused on highlighting ontological, epistemological, and axiological issues. Ontologically, the research was interested in the multiple realities surrounding the good life opportunities of young women of Turkish origin living in Germany, for example, how young women of Turkish origin viewed reality and experienced reality. Society constructs a reality which influences personal interpretations and experiences. From an epistemological perspective, knowledge gaps were identified to maximize the contribution to the knowledge production for literature concerning both the Capability Approach and migrant youth in Germany. 
The data which is collected from focus groups and individual life history interviews were triangulated. The term 'triangulation' is reserved for instances where methods are combined for the purpose of confirmation (Lambert \& Loiselle 2007, 230). Triangulation is defined as researchers taking different perspectives on an issue being studied or, more generally speaking, for answering research questions (Flick 2014).

\section{Procedures}

The ethical aspects of conducting research with young women were considered from the beginning of the research. At the initial stage, description of the research project and all the data collection materials (interview guidelines and the socio-demographic questionnaire) was sent to the school to inform the headteacher, teachers, parents, and participants. The researcher`s biography and contact details were also attached to the documents to give a detailed explanation to all partners. All of the young women took the documents home and brought a signed approval from their parents to participate in the interviews.

Before each interview started, the researcher explained the aims and goals of the research project, answered the participants' questions and made sure the participants still wanted to participate in the research. It was made clear that they could leave the research project at any time and participants did not have to answer any questions if they did not feel comfortable.

The data collection started after the participants' final approval. Also, in some of the meetings, a teacher was present during the interview for a while to comfort the participants. The research assistant, who spoke both Turkish and German, assisted during the whole data collection process. During the different phases of data collection, researchers kept in mind that some of the participants were under 18 years old and that they were studying in deprived areas of Germany. We tried to eliminate the effects of possible stigmatization.

During the preparation for data collection, researchers were careful that the data collection process should not reinforce stereotypes and stigmatization, exploit the young women or cause them stress.

Privacy and confidentiality was a central aspect of this research. The codes of ethics insist on protecting people's identities and research locations. All personal data ought to be secured or concealed and made public only behind a shield of anonymity (Christians 2011,66 ). As a researcher of this study identity of the participants and the names of the schools were kept anonym. All participants on the research report were called by another name to protect their identities.

The researcher approached the question of truth in this research with care, as Christians $(2011,66)$ discusses that accurate data is a cardinal principle in social codes as well. Fabrications, fraudulent materials, omissions, and contrivance are both non- 
scientific and unethical. When finding the truth of the data, the most appropriate data which would discuss the answers to the research questions was chosen.

\section{Analysis}

Girls discussed their aspirations and life plans both in the focus groups and in-depth individual life history interviews. Through interviews, girls highlighted the importance of school education and the importance of being an educated young woman in German society ${ }^{2}$. The sub-category was not used when the girls discussed education as a materialistic value. Also, the sub-category was not used if the girls confronted exclusionary or unequal treatment outside of the school. Education as an Aspiration was found to be the only overarching category without subcategories. The category defined the main values in participants` lives, which emerged when the girls discussed why they wanted to get an education. Education was found to be not only for the financial gain of the girls. In their opinion, education was a valuable aspiration. The girls clearly meant that if they got a better education, they would have better prospects for life in Germany, which would also help them to raise their voice and be positively represented in the German society. The girls' understanding of education was more abstract than concrete.

Participants discussed that education is a fundamental aspect of a good life. If they have a good education, they may have better labor opportunities in the future for a better life. In the interviews, most participants pointed out that, in their lives, the most crucial to study and have a good career. After obtaining education and skills for a good work; they can think of other aspects of their lives.

\section{Findings}

In the below quote, Tuğba expresses the wish study more in order to have an occupation as she describes that she realized what kind of difficulties people have if they did not study and did not have an occupation. Their difficult situation in Germany might also play a role for them to raise their voices to be accepted as a part of German society.

2 The German Gymnasium (grades 5-12 or 5-13) is an academic secondary school that prepares pupils for a university education. It begins with the fifth grade (seventh in Berlin/Brandenburg). After grade 12 or 13 (depending on the state), students earn a diploma called das Abitur by passing an oral and written examination.

The Realschule (grades 5-10) may be a step below the Gymnasium.

The Hauptschule (grades 5-9 or 5-10) is generally considered the least demanding secondary school. The Hauptschule prepares pupils for vocational education, and most of the pupils work part-time as apprentices. Upon completion of the final Hauptschulabschluss examination, after grade 9 or 10. They also have the option of earning the more prestigious Realschulabschluss after grade 10. With that, the next step is often Berufsschule; an advanced technical/vocational school with a two-year course of apprenticeship and study.

Gesamtschule (grades 5-12 or 5-13): Some German states have this kind of school, which combines the three school types into a comprehensive school that is similar to an American high school. 
Girls interpreted that better education would bring more opportunities to be accepted in German society. Girls observed the experiences of their relatives in order to plan their future prospects. In the following quotes, girls highlighted their families are advising to choose high-rank career versus low rank in the societal hierarchy.

Tuğba: Your environment, I learned that people who studied have easier lives, so they that much later, do not have difficulties. My mother doesn't have an occupation. After she completed high school, she didn't go to school, she didn't go to university that is why she doesn't have an occupation that is why all she did is wasted. That is why I want to succeed something for not having difficulties later. For example, my grandfather, worked in a factory, coaling, so doing very hard jobs. Like that they are doing hard jobs because they didn't go to school and they didn't study. That is why I want to study, not to have the same.

Leyla: My mother says that don't do the cleaning, let others do for you and you work at a very high workplace. We might finish Abitur, going to university, a good university. Yes, my father says, I did mistakes, you don't suffer like me, save your life, he says.

Participants had high inspirations and aspirations for a career. In different focus group settings, participants mentioned to further their education and go to do Abitur (which allows one to access higher education in Germany) or to a vocational education to have a good job. Even in the Hauptschule interviews, girls highlighted that they try hard to do Abitur in order to have good vocational training. Participants perceived going to a lower level of education will not give them a life they would value.

Ada: For my mother and father, to be not insulted is very vital. I say that at that time if I have a job, everyone would say that girl studied, everyone would say.

Data revealed that their parents or people in their surrounding was verbally for getting a good education supported girls. It was not possible to examine how solid support girls could get from their families for school education or future planning. Quotes only revealed that their parents from a young age was to study and have high career aspirations have supported girls. Girls` meaning for education are; aspirations to be emancipated, to be independent and to live a life with their own resources to have an active role in Germany.

Discussion on life plans was also part of the interviews to understand deeply their motivations. In a different focus group and individual interviews, participants highlighted the importance ofindependence. All participants involved in the research had high career aspirations and goals. Some participants highlighted, they would like to live a life without being dependent on anyone. Girls conceptualized being independent in various spheres of their lives. Education is one aspect as a tool to access a good career choice. Girls emphasized that good career choices could support women economically to be independent and empower them to raise their voices. Ada: I want to go to university. I want to become a pilot.

Manolya: I want to become a doctor but I am afraid of not succeeding. But I want to do abitur first, later, it will be clearer what I will do later. 
Duru: I will also do abitur but don't know what I will do later. Not to depend on anyone, not to accept something from anyone, to get our own lives in our hands.

Continuing from the above discussion; quotes below revealed, girls` educational aspirations are strongly linked with inspirations to have the freedom to be an emancipated woman. Interestingly, girls emphasized that having freedom and being independent as their main aspirations. Participants also argued that being independent and having freedom are much valuable than having money. They were aware of gendered roles. Their life experiences had shown them being an emancipated woman is more acceptable in German society. According to their interpretations, being independent is safe rather than depending on someone.

Ece: Being independent. Besides liking, I don't know anyone, one opens completely a new page, there is only you, there is no one to save you or fail you, there is no one, you learn to live on your own legs. Like when you go to an island, people themselves with your own talents you try to stand, standing on your own legs, I would like to have a house, I would like to have a job, I wouldn't have money but I would turn myself, myself. You will go wherever you want, you will do whatever you like, and there will not be any chains to your feet.

Nevra: Exactly. For instance, tolerance is notable, do you understand, you will get what you want in life, do you understand, "do you understand what do I mean" (she said once again in German), so what the way, I would like to do things.

Also, data reveals that none-formal and informal education opportunities could enhance for girls to break their limits for better educational opportunities. Mainly, girls were emphasizing they spent time with their families, sports, and friends as their free time activities. Participants also highlighted there were not many activities in their neighborhood nor were they well informed about these activities. When their teachers offer them free time activities, they get engaged in these activities. In the following quotes, Ada emphasized that she did not find any place for herself after school. The reason for lack of integration would be for the girls, not to be able to find such activities that were culturally relevant or these activities might not be convenient for the girls. Extracurricular activities would be crucial for girls` life to find valuable activities to enhance their educational process besides school education.

Ada: There are not many places to go in Germany.

Interviewer: Are there any youth activities where you can take part? Can you participate in those? Duru: I didn't participate before I participated one. I didn't go recently. For instance, during our summer vacation, our teacher gave us a paper, brochure (.), that she gave, for instance near Rheine, old town, there so. The place is called XXXX. They do sports, athletics so, we could join so, offered like that. For those who could go. 
countries?

Duru: Yes of course as we live in Germany, we definitely go.

Girls highlighted that mosque-related activities were the only activities they were attending. These activities were not what girls preferred to attend in the beginning. Also, girls did not find these activities relevant to their needs.

Interviewer: What else do you do? Do you attend activities of Turkish associations or mosques?

Girls: Yes we do ((with a high voice tone))

Cemre: My mother took me by force 0 (laughter))

Leyla: Also my mother took me there but later it was good, fun, it was a good time with friends.

Duru: We were going to the mosque, we were learning every Saturday so that we were doing theater, we played a matter, first time me when I participated for the first time like that happened. Since then, after me, my small cousins went to say carols.

Elif: How can I say here, for people in our age, they don't do things to people, they don't offer something, for example in Turkey there are cafes for youth, here in XXXXX (the name of neighborhood where this young lady is living) there is only one café where young people go, there are only grandmothers there, only old people going there (laughs).

Deniz: My mother brings things, brochures, we look for summer offers and such, I am always looking, is always for little children or for example, theaters for older people.

\section{Discussion}

The social vulnerability of children and youth from migrant backgrounds has been an important topic for educational science research in Germany, because children and adolescents with a migrant background are at higher risk for social exclusion than native children and adolescents. Also, in 2014, the level of continuing education uptake among people with migrant backgrounds ( $8 \%$ ) was only half as much as that by people without migrant backgrounds (16\%). The levels are particularly low among people originating 
from Turkey (4.5\%)" (German Education Report 2016).

This discussion arises from concerns about the nature and consequences of immigration status for young Turkish women in Germany. From this perspectives, two goals of the research were identified: The first goal was; how girls from a Turkish origin living in Germany developed a positive view of themselves; such as empowerment, agency, emancipation, inspirations and aspirations as they were challenged at school and in the German society. The second goal was; how girls from a Turkish origin living in Germany interpreted challenges at school and in the wider society in seeking a good life: As a result the research aimed to investigate: how socially vulnerable Turkish immigrant young women interpreted a good life and a good school education; and how the young women actively used their agency to approach a good life and a good school education as they valued in Germany. The data were interpreted with the lenses of contemporary issues in the German society such as discourses on integration, educational opportunity, exclusion, inclusion, citizenship, and belonging. Girls' interpretation of their reality as being affected by school discourse was interpreted; schools' discourse was rooted from the main debates in the German society on immigrants and immigration.

Young people in urban areas were having obstacles to approach social activities. Free time activities would be also influencing girls`education and life achievements positively. Girls would benefit from extra-curricular activities to enhance educational opportunities to build a meaningful life in Germany.

As a result girls need various supports to organize their lives to approach their educational goals to improve their lives, raise their voice and have the good life they value. School education should be planned for incorporation with non-formal and informal education possibilities to enhance opportunities for the girls.

In the main category 'education and aspirations', the girls highlighted that being educated was a value in order to be heard and be a part of the German society. The Turkish origin girls anticipated that their unequal position in the German society would end when they are educated and have a profession to contribute to Germany. I posit that the girls desire to be educated should be responded to by providing equal educational opportunities linked with social welfare opportunities that the girls could have the freedom to choose and create a life that she values and finds meaningful. Creating a system where there are several opportunities to develop diverse identities would be crucial for a system that desires to create a good society.

During the interviews, girls gave many examples from their school education. These examples were used when the girls inspired education as an aspiration for their lives to build a good life for themselves not only material but also for being valued, accepted and raising their voices in the German society. Girls generally have negative school experiences with their teachers. All girls mentioned their negative relationships with their teachers, which affected their school achievement and their prospects for a good school education.

Also raising their voice meant contributing to Germany with other citizens of 
Germany. From this aspect, the girls aimed to develop identities where their Turkishness, Germaneness and Muslim identity were acknowledged and visible in the German society. The girls aspired to live in a society in which they were not expected to limit their diverse identities and express the richness of their identity of a single culture and background; which in reality they didn't belong to. The girls aspired for a society where ethnicity and religion were not restrictions but opportunities.

\section{Further Research Perspectives}

Analyzing the data of this research, two points would be significant for developing further research questions to investigate similar phonemes. The first point is young women have not discussed what does it mean to be a woman in their families, in Turkish community and in German society. Examining opportunities and vulnerabilities for the young women with gender perspective would be necessary for expansion of gender, equality and school education research in Germany. As a result of this research, significant concepts for vulnerability are national and ethnical identity, linked to identity citizenship and religion for limiting possibilities for a good life.

Significantly, Turkish origin young women, in different cities and different settings highlighted similar concepts intersection of; identity, citizenship and religion as limiting their opportunities in the German society. The data collection had started with without a prior literature review for a quality data Grounded Theory analysis. Findings of this research proposes further research on school education and health wellbeing of young women from Turkish origin and migrant origin women or youth; identity development, belonging, empowerment, agency of socially vulnerable youth for contributing to a positive transformation in a society and finally deprivation of collective capabilities for creating a good society because of racism, xenophobia, otherness, exclusion and discrimination against migrant origin people in Germany.

\section{References}

Baysu G., Phalet K., \& Brown R. 2011. "Dual Identity as a Two-edged Sword: Identity Threat and Minority School Performance." Social Psychology Quarterly 74(2):12143.

Bowskill M., Lyons E., \& Coyle A. 2007. "The Rhetoric of Acculturation: When Integration Means Assimilation.” British Journal of Social Psychology 46(4):793-813.

Christians C. G. 2011. "Ethics and Politics in Qualitative Research," in N. K. Denzin \& Y. V. Lincoln (Eds.), The Sage Handbook of Qualitative Eesearch. California: Sage Publication (61-81). 
Crul M. \& Mollenkopf J. 2012. "The Second Generation," in M. Crul \& J. Mollenkopf (Eds.), The Changing Face of World Cities: Young Adult Children of Immigrants in Europe and the United States. New York: Russell Sage Foundation (3-25).

Flick U. 2014. An Introduction to Qualitative Research. London - Thousand Oaks - New Delhi - Singapore: Sage Publications.

Herzog-Punzenberger B. \& Schnell P. 2012. „Die Situation mehrsprachiger Schüler/ innen im österreichischen Schulsystem-Problemlagen, Rahmenbedingungen und internationaler Vergleich“. Nationaler Bildungsbericht Österreich 2:229-68.

Lambert S. D. \& Loiselle C. G. 2007. „Health Information - Seeking Behavior.“ Qualitative Health Research 17(8):1006-19.

Ministers of Education and Cultural Affairs of the Länder in the Federal Republic of Germany and the Federal Ministry of Education and Research. 2016. "Education in Germany 2016: An Indicator-based Report Including an Analysis of Education and Migration". Retrieved from Federal Ministry of Education and Research: https://www.bmbf.de/files/6001820e_kf-englisch_barrierefrei.pdf

Nussbaum M. 2000. “Women's Capabilities and Social Justice.” Journal of Human Development 1(2):219-47.

Robeyns I. 2005. "Sen's Capability Approach and Gender Inequality: Selecting Relevant Capabilities," in B. Agarwal, J. Humphries, \& I. Robeyns (Eds.), Amartya Sen's Work and Ideas: A Gender Perspective. Abingdon, Oxon: Routledge (64-94).

Schneider J. \& Crul M. 2012. "Comparative Integration Context Theory: Participation and Belonging," in M. Crul, J. Schneider, \& F. Lelie (Eds.), The European Second Generation Compared: Does the Integration Context Matter? Amsterdam: Amsterdam University Press (19-38).

Sen A. 1999. Development as Freedom. Oxford - New York: Oxford University Press.

Wilpert C. 2013. "Identity Issues in the History of the Postwar Migration from Turkey to Germany." German Politics and Society 31(2):108-31. 
Pinar Burcu Güner (Bielefeld)

\title{
Education as an Aspiration for Girls of Turkish Muslim Origin in Germany
}

\begin{abstract}
In order to find the inequalities in the life of socially vulnerable Turkish origin girls; the present research conceptualized how ethnicity and migration background deprive or enhance capabilities (opportunities) of the $2 \mathrm{nd}$, 3rd and 4th generation girls with a Turkish origin living in Germany. Data for research were collected in consultation with colleagues working in the field of youth and education in the Federal State of North Rheine Westphalia. The participants were girls between the ages of 13 and 21 years residing in North Rhine Westphalia`s (NRW) socio-economically vulnerable areas.
\end{abstract}

Keywords: Turkish origin girls, capabilities, education, aspiration, Germany

Ethics in Progress (ISSN 2084-9257). Vol. 9 (2018). No. 2, Art. \#7, pp. 87-98.

Creative Commons BY-SA 3.0

Doi:10.14746/eip.2018.2.7 